\title{
Effect of Cinepazide Maleate Combined with Promethazine Hydrochloride in the Treatment of Emergency Vertigo
}

\author{
JunYi*, Yincai Zhou, Xinghao Cheng
}

The Second People's Hospital of Taizhou City, Qinzhou 225599, Jiangsu Province, China

\begin{abstract}
[Abstract] Objective: To explore the effect of cinepazide maleate combined with promethazine hydrochloride in the treatment of emergency vertigo. Methods: 48 cases of emergency vertigo patients in our hospital from November 2017 to November 2019 were divided into experimental group (24 cases, treated with cinepazide maleate combined with promethazine hydrochloride) and control group ( 24 cases, treated with cinepazide maleate). The clinical efficacy, symptom relief time, adverse reactions and quality of life were compared. Results: The total effective rate of the experimental group $(95.83 \%, 23 / 24)$ was higher than that of the control group $(75.00 \%)$, The remission time of nausea and vomiting $(1.75 \pm$ $0.22) \mathrm{d}$, vertigo $(3.54 \pm 0.63) \mathrm{d}$, deafness and tinnitus $(3.47 \pm 0.58) \mathrm{d}$, night sweats $(3.05 \pm 0.33) \mathrm{d}$ in the experimental group were shorter than those in the control group, $\mathrm{P}<0.05$; the incidence of adverse reactions in the experimental group $(8.33 \%, 2$ 1 24) was lower than that in the control group $(33.33 \%$, The scores of social function, material life attitude, physical health and psychological function in the experimental group were $59.14 \pm 7.23,54.05 \pm 8.04,53.58 \pm 8.86$ and $60.11 \pm 8.44$ respectively, $\mathrm{P}<0.05$. Conclusion: In the process of clinical treatment of emergency vertigo patients, the combined application of cinepazide maleate and promethazine hydrochloride has definite curative effect, can relieve clinical symptoms in a short time, has less adverse reactions, and improves the quality of life of patients to a certain extent, which is worthy of promotion.
\end{abstract}

Key words: Cinepazide maleate; Promethazine hydrochloride; Emergency vertigo; Effect

Publication date: May, 2021; Publication online: 31 May, 2021

*Corresponding author: JunYi, 2104623526@qq.com

\section{Introduction}

Vertigo is a common disease in internal medicine, mainly including true vertigo and false vertigo. After the onset of the disease, patients will appear dizziness, accompanied by visual rotation, nausea and vomiting and other symptoms, and subjective discomfort is strong, and even patients will be cold limbs, cold sweat or pale ${ }^{[1]}$. There are many causes of vertigo, especially cerebrovascular disease, cold history, neurological dysfunction and drug poisoning. Incidence rate will directly affect patients' work and life. At present, the clinical treatment of vertigo generally choose vasodilation, sedation, vitamin supplement and diuretics and other methods, but it is difficult to obtain curative effect in a short time $^{[2]}$. Thus, in-depth study and analysis of the clinical treatment of emergency vertigo patients has a certain practical significance.

\section{Data and methods}

\subsection{Baseline data}

48 cases of emergency vertigo patients treated in our hospital from November 2017 to November 2019 were selected for statistical comparison. According to the admission number, they were divided into two groups: the control group ( 24 cases), male 15 cases, female 9 cases, the upper and lower limits of age were 76 years old and 23 years old, the median age was $(48.12 \pm 2.78)$ years old; the experimental group (24 cases), male 14 cases, female 10 cases, the upper and lower limits of age were 79 years old and 21 years old, the median age was $(48.15 \pm 2.78)$ years old 73) years old. The basic data of the two groups were $p>$ 0.05 , which was considered comparable. 
Inclusive criteria: acute vertigo diagnosed by clinical symptoms; no drug contraindications; complete clinical data.

Exclusion criteria: significant fluctuation of vital signs; difficult communication; abnormal mental state.

\subsection{Method}

The control group was treated with cinepazide maleate, $500 \mathrm{ml}$ of $0.9 \%$ sodium chloride solution and cinepazide maleate injection (national drug approval: h20153059, approval date: March 27, 2015 manufacturer: Fujian Jinshan biopharmaceutical Co., Ltd., English Name: cinepazide maleate) After mixing $320 \mathrm{mg}$, the drug was given intravenously once a day at a rate of $100 \mathrm{ml}$ per hour ${ }^{[3]}$.

The experimental group was treated with cinepazide maleate combined with promethazine hydrochloride, and the usage and dosage of cinepazide maleate were the same as those of the control group, and promethazine hydrochloride was used in parallel (national medicine standard word: h52020023, approval date: February 9, 2015 manufacturer: Tongjitang (Guizhou) Pharmaceutical Co., Ltd. of Chinese medicine group, English Name: promethazine hydrochloride) Tablets) three times a day at a dose of $2.5 \mathrm{G}$.,

Both groups were treated for one week.

\subsection{Evaluation index}

\subsubsection{The clinical efficacy and adverse reactions were} compared and analyzed.

The evaluation standard of clinical treatment effect refers to the "diagnostic and curative effect standard of traditional Chinese medicine", which is composed of three parts: markedly effective, effective and ineffective. Significant effect means that after treatment, the clinical symptoms of the patient have completely disappeared, and there is no shaking movement when adjusting the head posture, walking and sitting, and there are no accompanying symptoms; effective means that after treatment, the clinical symptoms are relieved, and there is a sense of rotation, which will partially affect daily life and work; ineffective means that after treatment, the patient's condition does not change or even worsen. The total effective rate of clinical treatment was the sum of significant efficiency and effective rate ${ }^{[4]}$. The main adverse reactions were neutropenia, rash and diarrhea.

2.3.2 The symptom relief time and quality of life scores of the two groups were evaluated.

The main symptoms included deafness, tinnitus, night sweat, vertigo, nausea and vomiting; the quality of life indicators included social function, material life attitude, physical health, psychological function.

\subsection{Statistical analysis}

$\mathrm{T}$ test or $\chi 2$ test were used to measure data (, symptom remission time, quality of life score) or count data (\%, clinical efficacy, adverse reaction status) (the software was spss23.0). If $\mathrm{P}<0.05$, the data difference was confirmed to be statistically significant.

\section{Results}

\subsection{Comparison of clinical efficacy between experimental group and control group}

There was no significant difference in the total effective rate between the two groups $(\mathrm{P}<0.05)$ (Table 1$)$.

Table 1. clinical efficacy of the two groups (n /\%)

\begin{tabular}{cccccc}
\hline Group & n & Significant effect & Effect & Negative & Total effective rate \\
\hline Experimental group & 24 & 16 & 7 & 1 & 95.83 \\
Control group & 24 & 14 & 4 & 6 & 75.00 \\
X $^{2}$ & & & & 4.1812 \\
P & & & & 0.0408 \\
\hline
\end{tabular}

\subsection{Comparison of symptom relief time between the} two groups

Compared with the control group, the indexes of the experimental group were significantly higher $(\mathrm{P}<0.05)$ (Table 2).

Table 2. Analysis of symptom relief time in experimental group and control group $(\overline{\mathrm{X}} \pm \mathrm{S})$

\begin{tabular}{cccccc} 
Group & n & $\begin{array}{c}\text { Remission time of } \\
\text { nausea and vomiting }\end{array}$ & $\begin{array}{c}\text { Remission time } \\
\text { of dizziness }\end{array}$ & $\begin{array}{c}\text { Remission time of } \\
\text { hearing loss and } \\
\text { tinnitus }\end{array}$ & $\begin{array}{c}\text { Remission time } \\
\text { of night sweat }\end{array}$ \\
\hline
\end{tabular}




\begin{tabular}{cccccc}
\hline Experimental group & 24 & $1.75 \pm 0.22$ & $3.54 \pm 0.63$ & $3.47 \pm 0.58$ & $3.05 \pm 0.33$ \\
Control group & 24 & $3.38 \pm 0.64$ & $6.46 \pm 1.24$ & $4.89 \pm 0.74$ & $4.61 \pm 0.45$ \\
$\mathrm{~T}$ & & 11.7994 & 10.2850 & 7.3989 & 13.6953 \\
$\mathrm{P}$ & & 0.0000 & 0.0000 & 0.0000 & 0.0000 \\
\hline
\end{tabular}

\subsection{Study on adverse reactions of experimental group and control group}

The total incidence was compared between the two groups, $\mathrm{P}<0.05$ (Table 3).

Table 3. Comparison of adverse reactions between the two groups (n /\%)

\begin{tabular}{cccccc}
\hline Group & n & Granulocytopenia & Diarrhea & Rash & Total incident \\
\hline Experimental group & 24 & 0 & 1 & 1 & 8.33 \\
Control group & 24 & 2 & 3 & 3 & 33.33 \\
X $^{2}$ & & & & & 4.5474 \\
P & & & & & 0.0329 \\
\hline
\end{tabular}

3.4 Comparison of quality of life scores between the two groups
The indexes of the experimental group were compared with those of the control group, $\mathrm{P}<0.05$ (Table 4).

Table 4. Quality of life scores of experimental group and control group ( $\overline{\mathrm{X}} \pm \mathrm{s})$

\begin{tabular}{cccccc}
\hline Group & $\mathbf{n}$ & Social function score & Material life attitude score & Physical health score & Mental function score \\
\hline Experimental & 24 & $59.14 \pm 7.23$ & $54.05 \pm 8.04$ & $53.58 \pm 8.86$ & $60.11 \pm 8.44$ \\
group & & & & & \\
Control group & 24 & $45.58 \pm 2.06$ & $46.69 \pm 2.11$ & $40.12 \pm 6.18$ & $40.21 \pm 6.17$ \\
$\mathrm{~T}$ & & 8.8363 & 4.3377 & 6.1042 & 9.3249 \\
$\mathrm{P}$ & & 0.0000 & 0.0001 & 0.0000 & 0.0000 \\
\hline
\end{tabular}

\section{Discussion}

Vertigo belongs to the head neuropathy, which is a position illusion or movement illusion related to spatial location. During the onset of the disease, the patient will consciously or feel the rotation of foreign objects, and there is also the possibility of combined dizziness ${ }^{[5]}$. Among them, vertigo includes central vertigo and peripheral vertigo. The former is mainly related to cerebral nerve and brain tissue lesions, accounting for $30 \%$ of the total number of vertigo patients. The latter is mainly caused by ear diseases. During the onset, the hearing level will decline, and at the same time, it will show deafness and tinnitus, and even different degrees of autonomic nervous system performance. On this basis, craniocerebral trauma, inflammatory demyelinating disease and neck lesions are more likely to induce this disease.

In clinic, antiemetic drugs and vasodilators are the main treatment methods. If necessary, sedative drugs should be taken in combination with the patient's condition to effectively relieve the symptoms of vertigo. However, the curative effect of the above treatment methods in the treatment of patients with acute vertigo is not exact, it is easy to appear a series of adverse reactions in the case of long-term medication, and eventually make the original condition worse ${ }^{[6]}$.

Cinepazide maleate belongs to a new generation of endogenous adenosine synergist, which can dilate blood vessels and promote the nutritional metabolism of cells. The pharmacological effects of this drug are as follows:

- It can inhibit AMP (cyclic adenosine monophosphate) phosphodiesterase and increase the number of AMP;

- The effects of cyclic adenosine monophosphate and adenosine were significantly enhanced to achieve the goal of reducing oxygen consumption;

- To prevent neutrophils and oxygen free radicals from forming chemotaxis on vascular endothelial cells, platelet aggregation should be inhibited, so that the deformability and toughness of cells can be enhanced, and blood viscosity can be decreased, so as to achieve the goal of improving microcirculation 
perfusion;

- Calcium ion is blocked to enter vascular smooth muscle cells, and vascular smooth muscle relaxes, which makes cerebral vessels, coronary vessels and peripheral vessels dilate, and reduces vascular resistance, so as to achieve the purpose of relieving vasospasm and effectively increase blood flow;

- The cerebral blood flow was significantly increased to achieve the purpose of improving cerebral metabolism.

Promethazine hydrochloride is an antihistamine drug, and its basic pharmacological effects are as follows:

- The permeability increased significantly to dilate capillaries, relieve local edema, prevent platelet aggregation and concentrate whole blood;

- The stress of brain stem reticular ascending activation system was indirectly reduced, the central anti motion effect was exerted, and the patients' fear, tension and anxiety were relieved;

- Inhibition of the chemosensory area of the medulla oblongata is conducive to the exertion of the antiemetic effect ${ }^{[7]}$;

- The central anticholinergic property can act on the sensory receptor of midbrain, vestibule and vomiting center, block the excitation of cholinergic prominent labyrinth impulse in vestibular nucleus, and then enhance the efficacy of dizziness and vomiting, increase the local cerebral blood flow, relieve cerebral vasospasm, and achieve the goal of improving cerebral circulation.

In the study, the experimental group combined with cinepazide maleate, promethazine hydrochloride treatment, the indicators compared with the control group, $\mathrm{P}<0.05$.
Therefore, the effect of drug combination is more ideal.

\section{References}

[1] Zhang C. Clinical effect of cinepazide maleate combined with promethazine hydrochloride in the treatment of emergency vertigo [J]. Healthy vision, 2020 (16): 93.

[2] Wang ZY . Analysis of the value of cinepazide maleate combined with promethazine hydrochloride in the treatment of emergency vertigo [J]. Electronic Journal of integrated traditional Chinese and Western medicine, 2020,8 (1): 62,77.

[3] Cheng BF. Effect observation of cinepazide maleate combined with promethazine hydrochloride in the treatment of emergency vertigo $[\mathrm{J}]$. Contemporary medicine, 2020,26 (25): 6-7.

[4] Deng YH. Clinical efficacy of cinepazide maleate combined with promethazine hydrochloride in the treatment of emergency vertigo [J]. Diet and health care, 2019,6 (45): 57-58.

[5] Chen G. Observation on the therapeutic effect of cinepazide maleate combined with promethazine hydrochloride in emergency treatment of vertigo [J]. China Health Nutrition, 2019,29 (10): 273-274.

[6] Liang XB. Clinical effect of cinepazide maleate combined with promethazine hydrochloride in the treatment of emergency vertigo [J]. Health Care Guide, 2019 (33): 36.

[7] Zhou W. Analysis of the efficacy of cinepazide maleate combined with promethazine hydrochloride in the treatment of patients with emergency vertigo $[\mathrm{J}]$ Contemporary Medicine, 2019,25 (9): 145-146. 